\title{
Study on Structure of Labour Force Divided by Economic Sector: HCM, Vietnam Case
}

\author{
Vu Thi Kim Hanh \\ University of Economics and Law, \\ Vietnam National University Ho Chi Minh City \\ *Corresponding author details: Vu Thi Kim Hanh; \\ vtkhanh.ti@gmail.com, hanhvtk20702@sdh.uel.edu.vn
}

\begin{abstract}
Labour force plays a crucial role and it is the strategy of a country. The paper has objective to assess how impact of labour force structure is divided by economic sectors on logistics transport development in Ho Chi Minh (HCM), Vietnam. Author uses Estimating Logistics regression by Maximum Log Likelihood (LRML) and Assessing fit of a Logistics Regression (AFLR) with the time series data between 2005 and 2019. The notable results are cumulative percentage (\%) of impact of Labour force on state sector, Labour force on outside state sector and Labour force on foreign investing sector, ranging from $14 \%$ to $100 \%$. The lowest level is $10 \%$ in 2005 . The highest level is $100 \%$ in 2019 . Cumulative \% of logistics transport development impacted was at the lowest level of $7 \%$ and the highest level of $100 \%$. The impact level fluctuated upwards between 2006 and 2015. The Cumulative \% of impact of Labour force on state sector, Labour force on outside state sector and Labour force on foreign investing sector, and Cumulative \% of logistics transport development were impacted at different levels.
\end{abstract}

Keywords: labour force; logistics; transport; HCM; Ho Chi Minh; Vietnam; logistics regression; likelihood; LRML; AFLR

\section{INTRODUCTION}

Labour force plays a crucial role in a country. In any eras, or any socio-economic form, labour force always plays a decisive role, it directly impacts on the development process of a nation. Labour force is a major factor, it is the source and the main driving force that creates the production force, which is the factor that determines the speed and sustainable development of new production methods in an economy, especially an economy in the context of integration and internationalization. Therefore, it is impossible not to take care of labour force development. Labour force is very important. However, the distribution of labour force by economic sectors is much more important, especially in underdeveloped and developing countries. Each economic sector has its own decisive role in contributing GDP to the state budget. Therefore, the strategy of labour force allocation has much more effect on the economy of a nation. In order to achieve economic growth and have it developed, the country needs to have a harmonious, synchronous, balanced and scientific distribution of labour force for each economic field with its own characteristics.

[1] The reduction of the gap of the gender labour force participation is driven by higher entry of women, especially women who have more education. This results in intrahousehold adjustments in work dynamics, with women entering the labour force to offset the lost income of male partners who left the labour force. The trade liberalization increased female workers' unemployment rate and reliance on part-time jobs (Tibor Besedeš, Seung Hoon Lee, Tongyang Yang, 2021). [2] Tiebei Li, Jago Dodson, Xavier Goldie (2021) supposed that "Understanding the productivity effects of worker commuting burdens is essential for appraisals of urban planning and investment strategies designed to improve urban productivity.
It is found that the labour force in areas experiencing high commuting burdens exhibit lower levels of engagement with job markets. This research further reveals important variations in such relationships across diverse industry and occupation groups". [3] In Korea, proportion of aggregate labour force shows a reducing trend while masking the divergence in labour force's share at the industry level. At the industry level, analysis provides evidence that in major capital-intensive industries with high substitutability between capital and labour force like electronics, an increase in the capital-to-labour ratio tends to be associated with a fall in the labour force share. It is given that the rapid growth in value-added, these industries play a key role in the declining proportion of aggregate labour force. Service industries for example finance which has rapid labouraugmenting technological progress and low substitutability, and they have also contributed to the declining aggregate labour share (Eunbi Song, 2021).

The objective of this paper is to assess the impact of labour force structure divided by economic sector on logistics transport development.

\section{LITERATURE REVIEW}

[4] In United Kingdom, the industrial and service sectors already accounted for $40 \%$ of the labour force in 1381 . There was a substantial further shift of labour out of agriculture that occurred between 1522 and 1700 . Agricultural labour productivity led to the basis of increased employment in the industry and service sector from the beginning of seventeenth century.

Thereafter, and increased output of industry during the Industrial Revolution owed more to gains in labour productivity consequent upon mechanization than the 
expansion of employment (Stephen Broadberry, Bruce M.S.Campbell, Basvan Leeuwen, 2013). [5] Unemployment benefits have an impact on labour force participation decisions and individuals are more likely to participate in the labour force and to actively search for a job (Wolfgang Lechthaler, Patrick Ring, 2021). [6] The smaller the value of the extensive-margin labour force supply elasticity is, the stronger the procyclical values of non-market activities channel is. The wage rigidity helps, due to it mitigates increases in the return to market work during expansions (Isabel Cairó, Shigeru Fujita, Camilo Morales-Jiménez, 2021). [7] In the United State of America, underlying data shows that labour-force participation rate, and duration of unemployment calculations contain numerous internal contradictions, so the considering issue is whether labourforce participation rate and unemployment depend on divide of labour force (Hie Joo Ahn, James D. Hamilton, 2021). [8] The employed population, the distribution of occupations and industries provide a first glance into the way the social norms and market dynamics create gender segregation in specific economic sectors. Salary differs by education, location, age, sector, industry, and occupation The salary gap and some other issues are also reflected over discrimination in the opportunities that women face to occupy different positions in their companies. Gender discrimination in the labour market is a substantial barrier to the economic development of countries (Gustavo Nicolas Paez, Myat SuTin, 2021). [9] There is an increase in the participation of women at their reproductive ages. The older labour force of adults will be declined in the future compared to more developed economies. Associated with population aging and longer life expectancy is to reduce the ratio between workers and retirees which affect the basic premise of the pay-as-you-go system (BernardoLanza Queiroz, Matheus Lobo Alves Ferreira, 2021). [10] Mobility of women with higher education levels should be considered.

Labour force participation of women increased considerably in the regions which is most affected by the destruction of men which have jobs and with relatively higher labour demand in occupations more likely to employ women. Women with higher levels of education are also more likely to move to regions which has higher labour demand in these occupations. For men, there is an increase of unemployment in response to regional declines in male labour demand (Gregory Verdugo, Guillaume Allègre, 2020). [11] İnsan Tunalı, Murat G.Kırdar, Meltem Dayığlu (2021) stated that "The evidence compiled confirms that Turkey has reached the turning point of the U-shaped pattern in female labour force participation observed in countries where agriculture initially accounts for a large fraction of employment. The related interruptions in rural areas and for low-educated women in urban areas. The least-educated women are more likely to participate, contrary to the belief that culture stands in the way". [12] Technological advances raise productivity and growth, but it also likely to reshape labour markets. It is confirmed that labour force worked in fields where careers are easily changed, and it is easy to resign jobs. Encouragingly, the higher spending on active labour force programs and education can reduce negative impact of the participation of technological change (Francesco Grigoli, Zsoka Koczan, PetiaTopalova, 2020). [13] In France, a two-sector economy with endogenous allocation of the labour force between sectors and social networks favour the transmission of job information. Social networks can induce sector concentration even when sectoral productivities and entry costs are perfectly symmetric. Moreover, it is confirmed that social networks can also trap workers in poorly productive sectors (Manon Domingues Dos Santos, Emmanuelle Taugourdeau, 2021). [14] Werner Roeger, Janos Varga, Jan in 'tVeld et al., (2021) found "A general trade-off between an increase in employment for a particular group and the income of the average group member relative to income per capita. Reforms which aim at increasing employment of low- and mediumskilled workers, are associated with a fall in low- and mediumskilled wages relative to income per capita. Capital owners generally benefit from labour market reforms, with an increasing share of profits in total income that can be attributed to limited entry into the final goods production sector".

\section{METHODOLOGY}

Study framework

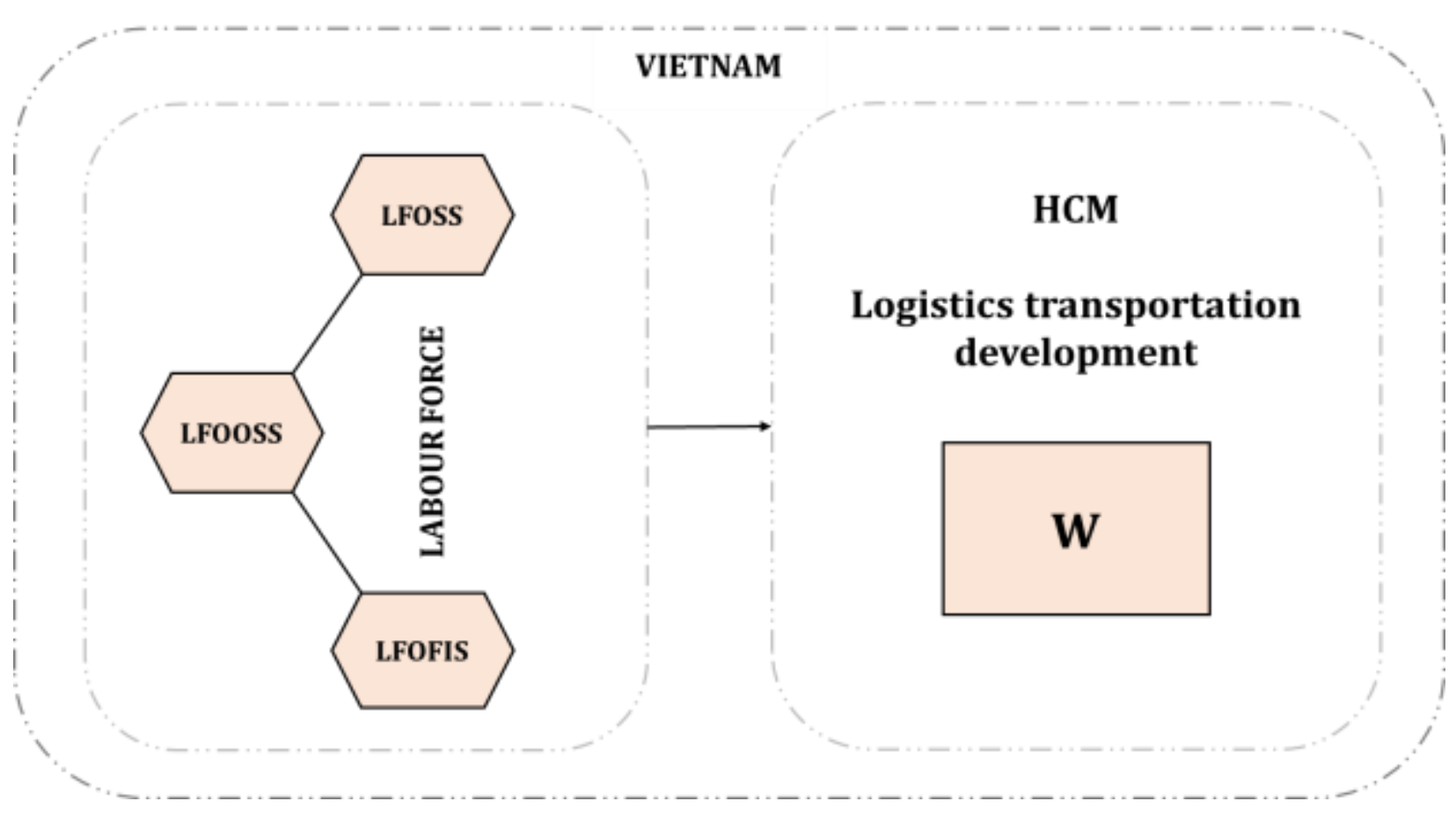


Variables of study framework

- Independent variables

LFOSS is labour force on state sector in terms of the whole economy of Vietnam, unit is a thousand people.

LFOOSS is labour force on outside state sector in terms of the whole economy of Vietnam, unit is a thousand people.

LFOFIS is labour force on foreign investing sector in terms of the whole economy of Vietnam, unit is a thousand people.

\section{- Dependent variables:}

W represents five dependent variables below Goods productivity calculated on labour of logistics transport industry (LTI), unit is a thousand tons over total labour.

Passenger productivity calculated on labour of LTI, unit is a million people over total labour.

Goods productivity calculated on capital of LTI, unit is a thousand tons over total capital.

Passenger productivity calculated on capital of LTI, unit is a million people over total capital.

$\mathrm{X}$ is Gross domestic products.

\section{HYPOTHESIS}

$\mathrm{W}=1: \mathrm{W}$ is impacted by LFOSS, LFOOSS, LFOFIS

$\mathrm{W}=0: \mathrm{W}$ is not impacted by LFOSS, LFOOSS, LFOFIS

- Estimating Logistics regression by Maximum Log Likelihood (LRML) and Assessing fit of a Logistics Regression (AFLR)

Estimating Logistics regression by Maximum Log Likelihood (LRML)

$\operatorname{Impact}=\log \left(\frac{W(I)}{1-(W(I)}\right)$

$\log \left(\frac{W(I)}{1-(W(I)}\right)=\mathrm{a}_{0}+\mathrm{a}_{1} \mathrm{~A}_{1}($ LFOSS $)+\mathrm{a}_{2} \mathrm{~A}_{2}($ LFOOSS $)+$ $\mathrm{a}_{3} \mathrm{~A}_{3}$ (LFOFIS)

Where

$\mathrm{W}$ is given as a value to measure the probability of a variable.

I is short writing of impact ( $\mathrm{I}=$ impact)

$\mathrm{n}$ are positive integers which are $1,2,3, \ldots, \mathrm{n}$

$\mathrm{a}_{0}$ is the intersection of the vertical axis and line of regression

$\mathrm{a}_{1}, \mathrm{a}_{2}, \mathrm{a}_{3}$ are parameters that have been estimated by multivariate regression

$\mathrm{A}_{1}, \mathrm{~A}_{2}, \mathrm{~A}_{3}$ are prediction variables that representing LFOSS LFOOSS, LFOFIS, respectively.

(1) $\mathrm{P}=\frac{e^{-\log (\text { score })}}{1+e^{-\log (\text { scor })}}$

As equation 1 states, Where,

$e^{-\log (\text { score })}=e^{-\log (\log (W))}$

$=$

$\mathrm{e}^{-\log (\text { Intercept's Coefficient+sumproduct (coefficient[A1:A3, inputdata] A1:A8) }}$

$1+e^{-\log (\text { score })}=1+e^{-\log (\log (W))}$

$=1$

$\mathrm{e}^{-\log (\text { Intercept's Coefficient+sumproduct (Coefficient [A1:A3, inputdata] A1:AE) }}$
Score $=\log (\mathrm{W})=$ Intercept's Coefficient + sumproduct (coefficent $\mid A_{1}: A_{3}$, inputdata| $A_{1}: A_{3}$ )

Coefficients of $A_{1}, A_{2}, A_{3}$ are parameters estimated by multivariate regression in which $\mathrm{A}_{1}, \mathrm{~A}_{2}, \mathrm{~A}_{3}$ are independent variables, $\mathrm{W}$ is dependent variable. They are then estimated by LRML.

Intercept is intersection between vertical axis and regression line which is the paramater estimated by LRML

Sumproduct is the formula to calculate the scores independent variables $A_{1}, A_{2}, A_{3}$ based on the actual values in condition with both rows and columns

$$
\text { (2) W's Probability }=\frac{e^{-\log (\operatorname{score} \mid \mathrm{A} 1: \mathrm{A} 3)}}{1+e^{-\log (\operatorname{score} \mid \mathrm{A} 1: \mathrm{A} 3)}}
$$

As equation 2 states the Probability of $\mathrm{W}$ to happen, where, Likelihood (LLHD):

$\mathrm{W}=1$ is to show $\mathrm{LH}=$ probability of $\mathrm{W}$

$\mathrm{LLHD}=\frac{e^{-\log (\text { score } \mid \mathrm{A} 1: \mathrm{A} 3)}}{1+e^{-\log (\text { score } \mid \mathrm{A} 1: \mathrm{A} 3)}}$

$\mathrm{W}=0$ that means $\mathrm{LLHD}=1-\mathrm{W}(\mathrm{E})$

$\operatorname{LLHD}=\frac{1-e^{-\log (\operatorname{score} \mid \mathrm{A} 1: \mathrm{A} 3)}}{1+e^{-\log (\operatorname{score} \mid \mathrm{A} 1: \mathrm{A} 3)}}$

Log - Likelihood $=$ Logarit of LLHD

$\mathrm{W}=1: \log$ likelihood $=\mathrm{Ln}$

$\operatorname{Ln}=\left(\frac{e^{-\log (\text { score } \mid \mathrm{A} 1: \mathrm{A} 3)}}{1+e^{-\log (\text { score } \mid \mathrm{A} 1: \mathrm{A} 3)}}\right)$

$\mathrm{W}=0:$ Log likelihood $=\mathrm{Ln}$

$\operatorname{Ln}=\left(\frac{1-e^{-\log (\operatorname{score} \mid \mathrm{A} 1: \mathrm{A} 3)}}{1+e^{-\log (\text { score } \mid \mathrm{A} 1: \mathrm{A} 3)}}\right)$

Maximum LLHD $=\sum_{3}^{1} A$ (Likelihood)

Using solver Parameters by:

Setting Objective $=\sum_{3}^{1} A$ (LLHD)

Maximize by changing coefficient of independent variables $A_{1}, A_{2}, A_{3}$ and coefficient of intercept.

Selected solving method: CRG Nonlinear

\section{Assessing fit of a Logistics Regression (AFLR)}

Sort Score from Largest to Smallest

$W$ is impacted by three independent variables $\left[A_{1}, A_{2}, A_{3}\right]_{\mathrm{im}}$

$\mathrm{W}_{\mathrm{im}(\mathrm{t})}=\mathrm{W} \mid 1 / 0$

$\mathrm{W}_{\mathrm{im}(\mathrm{t})+1}=\mathrm{W}_{\mathrm{imt}}+\mathrm{A} / \mathrm{DV}_{\mathrm{t}}$

Propensity rankings (PR) by ranking number from $t_{0}$ to $t_{n}$ where $t$ is time, 0 and $n$ are numbers in order

Cumulative percentage $(\%)$ of impact $=\frac{\operatorname{Wim}(t)}{\operatorname{Wim}(n) I}$

Cumulative $\%$ of $\mathrm{W}$ be impacted $=\frac{\mathrm{PR}(\mathrm{t})}{\mathrm{PR}(\mathrm{n})}$

Charting scatter 
THEORETICAL BASIS OF LOGISTICS TRANSPORTATION

[15] There is an existence of a capacity constraint within the public transport mode. The congestion interactions between cars and buses are associated with the transfer of passengers at bus stops. The non-motorised transport is considered that it impacts on optimal public transport pricing policy (David A.Hensher, 2020). [16] S. Bista, I. Debache, B. Chaix (2020) stated that "The physical activity and sedentary behaviours are related to transport activity. Transport policies encourage people to reach daily recommendations of physical activity.
In addition to active transport modes, encouraging people to use public transport increases physical activity and reduces sedentary time". [17] Logistics transportation is often considered a mode of transport which is used by train, tram, bus and other vehicles (Long T. Truong, GrahamcCurrie, 2019).

\section{DATA SOURCE}

Data is time series between 2005 and 2019. All data are from HCM Statistics Department and HCM Statistical Yearbook.

\section{STUDY RESULTS}

TABLE 1: Output Result of Multivariate Regression

\begin{tabular}{|c|c|c|c|}
\hline \multicolumn{2}{|c|}{ R square (RS) } & \multicolumn{2}{c|}{$0.22027038(22 \%)$} \\
\hline \multicolumn{2}{|c|}{ Adjusted R Square (ARS) } & \multicolumn{2}{|c|}{$0.00761685(0.76 \%)$} \\
\hline \multicolumn{2}{|c|}{ Significance F (SF) } & Value of Coefficients & P-Value \\
\hline \multirow{2}{*}{ Independent variables } & Coefficients & 10.75036461 & 0.20884386 \\
\cline { 2 - 4 } & $\mathrm{a}_{0}$ & -0.001604095 & 0.45217152 \\
\hline $\mathrm{A}_{1}$ & $\mathrm{a}_{1}$ & $-4.50119 \mathrm{E}-05$ & 0.70810545 \\
\hline $\mathrm{A}_{2}$ & $\mathrm{a}_{2}$ & -0.000223837 & 0.71071053 \\
\hline $\mathrm{A}_{3}$ & $\mathrm{a}_{3}$ & & \\
\hline
\end{tabular}

Source: Compiled result by author

With RS $=0.22027038(22 \%)$, ARS $=0.00761685(0.76 \%)$ is to mean that the input data has been explained by the output of multivariate regression model is $0.76 \%$. The model has statistical significance at 0.41465157 . The Coefficients of a0, a1, a2, a3 are 10.75036461, $0.001604095,-4.50119 \mathrm{E}-05,-0.000223837$, respectively.
The Coefficients of $\mathrm{a}_{0}, \mathrm{a}_{1}, \mathrm{a}_{2}, \mathrm{a}_{3}$ are to be used as parameters to have Maximum Likelihood in the step of Estimating Logistics regression by Maximum Log Likelihood which will presented in table 2 .

TABLE 2: Estimating Logistics regression by Maximum Log Likelihood

\begin{tabular}{|c|c|c|c|c|c|c|c|c|c|}
\hline \multirow{2}{*}{\multicolumn{2}{|c|}{$\begin{array}{l}\text { Parameters after } \\
\text { Maximum } \\
\text { likelihood }\end{array}$}} & Intercept & $\begin{array}{l}\text { Coefficient of } \\
\text { regression } \\
\text { output: } \\
\text { A1 }\end{array}$ & $\begin{array}{l}\text { Coefficient of } \\
\text { regression } \\
\text { output: } \\
\text { A2 }\end{array}$ & $\begin{array}{l}\text { Coefficient of } \\
\text { regression } \\
\text { output: } \\
\text { A3 }\end{array}$ & & & & \\
\hline & & 50.1483507 & -0.007971851 & -0.000201834 & -0.001143197 & & & $\begin{array}{l}\text { Maximum } \\
\text { Likelihood }\end{array}$ & -8.573815688 \\
\hline Year & No & LTD & $\mathrm{A} 1$ & $\mathrm{~A} 2$ & A3 & SCORE & $\begin{array}{c}\text { Probability } \\
\text { impacts on LTD }\end{array}$ & Likelihood & Log-Likelihood \\
\hline 2005 & 1 & 1 & $4,967.40$ & $36,694.70$ & $1,112.80$ & 1.870589374 & 0.866526458 & 0.866526458 & -0.143262636 \\
\hline 2006 & 2 & 1 & $4,916.00$ & $37,742.30$ & $1,322.00$ & 1.829744481 & 0.861731284 & 0.861731284 & -0.148811792 \\
\hline 2007 & 3 & 1 & $4,988.40$ & $38,657.40$ & $1,562.20$ & 0.793288331 & 0.688536963 & 0.688536963 & -0.373186277 \\
\hline 2008 & 4 & 0 & $5,059.30$ & $39,707.10$ & $1,693.60$ & -0.133997115 & 0.466550755 & 0.533449245 & -0.628391349 \\
\hline 2009 & 5 & 0 & $5,040.60$ & $41,178.40$ & $1,524.60$ & -0.088681675 & 0.4778441 & 0.5221559 & -0.649789076 \\
\hline 2010 & 6 & 0 & $5,025.20$ & $42,370.00$ & $1,729.20$ & -0.440318604 & 0.391665055 & 0.608334945 & -0.497029652 \\
\hline 2011 & 7 & 1 & $5,024.80$ & $43,423.80$ & $2,098.60$ & -1.072119366 & 0.255000248 & 0.255000248 & -1.36649076 \\
\hline 2012 & 8 & 0 & $5,017.40$ & $44,423.30$ & $2,249.80$ & -1.387712092 & 0.19977326 & 0.80022674 & -0.222860166 \\
\hline 2013 & 9 & 1 & $4,994.90$ & $44,994.60$ & $2,518.30$ & -1.630601496 & 0.163747979 & 0.163747979 & -1.809426746 \\
\hline 2014 & 10 & 0 & $4,893.20$ & $45,269.30$ & $2,868.10$ & -1.275198199 & 0.218368705 & 0.781631295 & -0.246372139 \\
\hline 2015 & 11 & 0 & $4,779.90$ & $45,132.80$ & $3,166.80$ & -0.685909936 & 0.334943545 & 0.665056455 & -0.407883347 \\
\hline 2016 & 12 & 0 & $4,702.30$ & $45,052.20$ & $3,591.00$ & -0.535970449 & 0.369125456 & 0.630874544 & -0.460648256 \\
\hline 2017 & 13 & 1 & $4,595.40$ & $44,905.40$ & $4,207.80$ & -0.359273969 & 0.411135329 & 0.411135329 & -0.888832851 \\
\hline 2018 & 14 & 0 & $4,525.90$ & $45,215.40$ & $4,541.20$ & -0.248940597 & 0.438084272 & 0.561915728 & -0.57640339 \\
\hline 2019 & 15 & 1 & $4,226.20$ & $45,664.60$ & $4,768.40$ & 1.789825086 & 0.85690583 & 0.85690583 & -0.15442725 \\
\hline
\end{tabular}

Source: Compiled result by author 
Table 2 is presented information of A1, A2, A3 and results of Maximum Log Likelihood that are parameters of regression coefficients of A1, A2, A3 are -0.001604095, $4.50119 \mathrm{E}-05,-0.000223837$, respectively, and intercept is 10.75036461. Coefficients are value after Maximum Log Likelihood of A1 $=-0.007971851, \mathrm{~A} 2=-0.000201834$,
A3 $=-0.001143197$ and intercept is 50.1483507, which is to show that the interception between the vertical axis and the regression lines is still over the horizontal axis., however it has been moved up from 10.75036461 to 50.1483507.

TABLE 3: Assessing fit of a Logistics Regression

\begin{tabular}{|c|c|c|c|c|c|c|c|}
\hline Year & No & LTD & $\begin{array}{c}\text { SCORE } \\
\text { (largest to } \\
\text { smallest) }\end{array}$ & $\begin{array}{l}\text { LTD be } \\
\text { impacted }\end{array}$ & $\begin{array}{l}\text { Propensity } \\
\text { rankings }\end{array}$ & $\begin{array}{l}\text { Cumulative } \% \text { of } \\
\text { impact }(\mathrm{A} 1, \mathrm{~A} 2, \mathrm{~A} 3)\end{array}$ & $\begin{array}{l}\text { Cumulative } \% \text { of } \\
\text { W impacted }\end{array}$ \\
\hline 2005 & 1 & 1 & 1.870589374 & 1 & 1 & $14 \%$ & $7 \%$ \\
\hline 2006 & 2 & 1 & 1.829744481 & 2 & 2 & $29 \%$ & $13 \%$ \\
\hline 2007 & 15 & 1 & 1.789825086 & 3 & 3 & $43 \%$ & $20 \%$ \\
\hline 2008 & 3 & 1 & 0.793288331 & 4 & 4 & $57 \%$ & $27 \%$ \\
\hline 2009 & 5 & 0 & -0.088681675 & 4 & 5 & $57 \%$ & $33 \%$ \\
\hline 2010 & 4 & 0 & -0.133997115 & 4 & 6 & $57 \%$ & $40 \%$ \\
\hline 2011 & 14 & 0 & -0.248940597 & 4 & 7 & $57 \%$ & $47 \%$ \\
\hline 2012 & 13 & 1 & -0.359273969 & 5 & 8 & $71 \%$ & $53 \%$ \\
\hline 2013 & 6 & 0 & -0.440318604 & 5 & 9 & $71 \%$ & $60 \%$ \\
\hline 2014 & 12 & 0 & -0.535970449 & 5 & 10 & $71 \%$ & $67 \%$ \\
\hline 2015 & 11 & 0 & -0.685909936 & 5 & 11 & $71 \%$ & $73 \%$ \\
\hline 2016 & 7 & 1 & -1.072119366 & 6 & 12 & $86 \%$ & $80 \%$ \\
\hline 2017 & 10 & 0 & -1.275198199 & 6 & 13 & $86 \%$ & $87 \%$ \\
\hline 2018 & 8 & 0 & -1.387712092 & 6 & 14 & $86 \%$ & $93 \%$ \\
\hline 2019 & 9 & 1 & -1.630601496 & 7 & 15 & $100 \%$ & $100 \%$ \\
\hline
\end{tabular}

Source: Compiled result by author

Table 3 gives information result of Assessing fit of a Logistics Regression, the cumulative $\%$ of impact $A_{1}, A_{2}, A_{3}$ on $\mathrm{W}$ is from $14 \%$ to $100 \%$, namely is years 2005,2006 , 2007 are $14 \%, 29 \%, 43 \%$, respectively. $2008-2011$ have $57 \%$ impacted, 71\% impact is between 2012 and 2015, three years have $86 \%$ impact i.e. 2016, 2017, and 2018, but only 2019 has $100 \%$ impact.
Cumulative $\%$ of $\mathrm{W}$ was impacted at the lowest percentage (7\%) in 2005, while the highest was $100 \%$ in 2019. Details from 2006 to 2015 are $13 \%, 20 \%, 27 \%, 33 \%, 40 \%, 47 \%$, $53 \%, 60 \%, 67 \%, 73 \%$, respectively. 2016 recorded $80 \%$, while 2017,2018 and 2019 recorded $87 \%, 93 \%$ and $100 \%$, respectively. The figures in table 3 is to mean that Cumulative \% of impact of $A_{1}, A_{2}, A_{3}$ and Cumulative \% of $\mathrm{W}$ be impacted are at different levels.

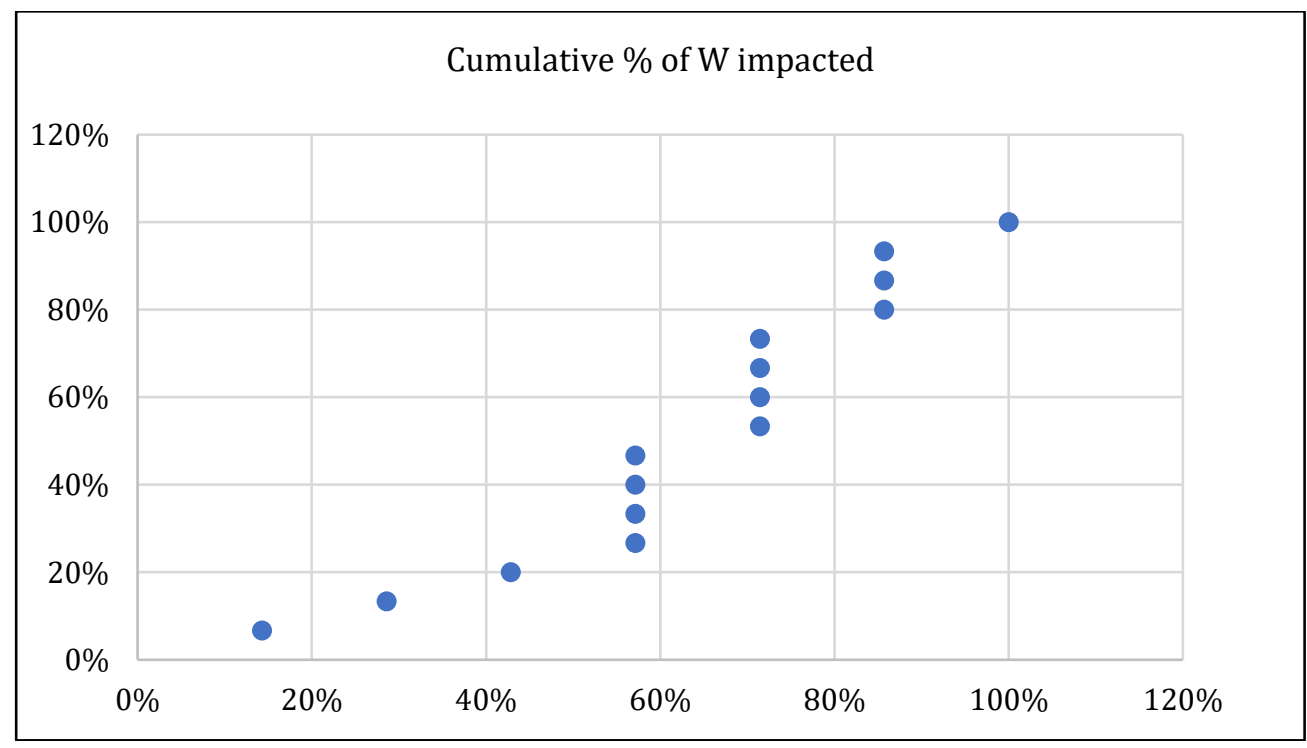

Source: Compiled result by author

FIGURE 1: Scatter chart of Cumulative $\%$ of $A_{1}, A_{2}, A_{3}$ and $W$ impacted 
The chart (figure 1) defined the scatter between Cumulative $\%$ of $\mathrm{W}$ impacted and Cumulative $\%$ of impact of $A_{1}, A_{2}, A_{3}$. Cumulative $\%$ of $W$ impacted is illustrated by vertical axis, Cumulative $\%$ of impact $A_{1}, A_{2}, A_{3}$ is described by horizontal axis. The scatter chart gives us the picture of single dots under $20 \%$ on both of the two axes, and there are four dots under $60 \%$ for both of the vertical and horizontal axes, while there are four dots inside $80 \%$ of the two axes. Three dots stay under $100 \%$, and finally, only one dot could reach $100 \%$ for both vertical and horizontal axes.

\section{DISCUSSION}

Based on study results presented in table 1, table 2 and figure 1 which show that the multivariate regression model was built suitably to input data at the statistical significance of 0.41465157 , the Coefficients parameters of multivariate regression model are acceptable. Coefficients value thereafter had been Maximum Log Likelihood of $A_{1}=$ $-0.007971851, \mathrm{~A}_{2}=-0.000201834, \mathrm{~A}_{3}=-0.001143197$ and intercept is 50.1483507, which means that the interception between the vertical axis and the regression lines is still over the horizontal axis. However, it has been moved up from 10.75036461 to 50.1483507. Result of Assessing fit of a Logistics Regression is Cumulative \% of impact $\mathrm{A}_{1}, \mathrm{~A}_{2}, \mathrm{~A}_{3}$ are from $14 \%$ to $100 \%$, detailing 2005 , 2006 , and 2007 with $14 \%, 29 \%, 43 \%$, respectively. 2008 2011 have $57 \%$ impacted, 71\% impact is between 2012 and 2015, 86\% impact is from 2016 to 2018, while $100 \%$ impact was recorded in 2019. Cumulative \% of W impacted was lowest at $7 \%$ in 2005 , and highest at $100 \%$ in 2019 . Between 2006 and 2015, the impact recorded were 13\%, $20 \%, 27 \%, 33 \%, 40 \%, 47 \%, 53 \%, 60 \%, 67 \%, 73 \%$, respectively. From 2016 to 2019 , they were is $80 \%, 87 \%$, $93 \%$ and $100 \%$, respectively. The figures in table 3 is to tell that Cumulative $\%$ of impact of $A_{1}, A_{2}, A_{3}$ and Cumulative $\%$ of $\mathrm{W}$ impacted are at different levels. The chart (figure 1) defined the scatter between Cumulative \% of $\mathrm{W}$ impacted and Cumulative $\%$ of impact of $A_{1}, A_{2}, A_{3}$. Cumulative $\%$ of $\mathrm{W}$ impacted is illustrated by vertical axis, Cumulative $\%$ of impact $A_{1}, A_{2}, A_{3}$ is described by horizontal axis. The scatter chart gives us the picture of single dots under $20 \%$ on both of the two axes, and there are four dots under $60 \%$ for both of the vertical and horizontal axes, while there are four dots inside $80 \%$ of the two axes. Three dots stay under $100 \%$, and finally, only one dot could reach $100 \%$ for both vertical and horizontal axes.

\section{CONCLUSIONS}

Cumulative \% of impact $\left(\mathrm{A}_{1}\right)$ LFOSS, $\left(\mathrm{A}_{2}\right)$ LFOOSS, $\left(\mathrm{A}_{3}\right)$ LFOFIS are from $14 \%$ to $100 \%$, the lowest level is $10 \%$ in 2005, the highest level is $100 \%$ in 2019 .

Cumulative \% of $\mathrm{W}$ impacted has the lowest level as $7 \%$ in 2005 , the highest as $100 \%$ in 2019 . The impact level fluctuated upwards between 2006 and 2015 in the likes of $13 \%, 20 \%, 27 \%, 33 \%, 40 \%, 47 \%, 53 \%, 60 \%, 67 \%$, and $73 \%$, respectively. The Cumulative $\%$ impact of $\left(\mathrm{A}_{1}\right)$ LFOSS, $\left(\mathrm{A}_{2}\right)$ LFOOSS, $\left(\mathrm{A}_{3}\right)$ LFOFIS and Cumulative $\%$ of $\mathrm{W}$ impacted are at different levels. The scatter chart showed that there is one dot is under $20 \%$, four dots under $60 \%$, four dots inside $80 \%$, three dots under $100 \%$ and only one dot reaching $100 \%$ levels for both vertical and horizontal axes.

\section{ACKNOWLEDGEMENT}

This research is funded by University of Economics and Law, Vietnam National University Ho Chi Minh City / VNUHCM.

\section{REFERENCE}

[1] Tibor Besedeš, Seung Hoon Lee, Tongyang Yang, 2021. Trade liberalization and gender gaps in local labor market outcomes: Dimensions of adjustment in the United States. Journal of Economic Behavior \& Organization. Volume 183, March 2021, Pages 574-588.
[2] Tiebei Li, Jago Dodson, Xavier Goldie, 2021. Urban structure, commuting burden, and employment status of labour forces in an Australian city. Journal of Transport Geography. Volume 93, May 2021, 103072.

[3] Eunbi Song, 2021. What drives labor share change? Evidence from Korean industries. Economic Modelling. Volume 94, January 2021, Pages 370-385.

[4] Stephen Broadberry, Bruce M.S.Campbell, Basvan Leeuwen, 2013. When did Britain industrialise? The sectoral distribution of the labour force and labour productivity in Britain, 1381-1851.

[5] Wolfgang Lechthaler, Patrick Ring, 2021. Labor force participation, job search effort and unemployment insurance in the laboratory. Journal of Economic Behavior \& Organization. Volume 189, September 2021, Pages 748-778.

[6] Isabel Cairó, Shigeru Fujita, Camilo Morales-Jiménez, 2021. The cyclicality of labor force participation flows: The role of labor supply elasticities and wage rigidity. Review of Economic Dynamics. Available online 10 February 2021.

[7] Hie Joo Ahn, James D. Hamilton, 2021. Measuring laborforce participation and the incidence and duration of unemployment. Review of Economic Dynamics. https://doi.org/10.1016/j.red.2021.04.005.

[8] Gustavo Nicolas Paez, Myat SuTin, 2021. Gender-based differences in Myanmar's labor force. World Development Perspectives. Volume 21, March 2021, 100299.

[9] BernardoLanza Queiroz, Matheus Lobo Alves Ferreira, 2021. The evolution of labor force participation and the expected length of retirement in Brazil. The Journal of the Economics of Ageing. Volume 18, February 2021, 100304.

[10] Gregory Verdugo, Guillaume Allègre, 2020. Labour force participation and job polarization: Evidence from Europe during the Great Recession. Labour Economics. Volume 66, October 2020, 101881.

[11] İnsan Tunalı, Murat G.Kırdar, Meltem Dayığlu, 2021. Down and up the " $U$ " - A synthetic cohort (panel) analysis of female labor force participation in Turkey, 1988-2013. World Development. Volume 146, October 2021, 105609.

[12] Francesco Grigoli, Zsoka Koczan, PetiaTopalova, 2020. Automation and labor force participation in advanced economies: Macro and micro evidence. European Economic Review. Volume 126, July 2020, 103443.

[13] Manon Domingues Dos Santos, Emmanuelle Taugourdeau, 2021. Social network, unemployment and sector trap: A theoretical model explaining the case study of Portuguese immigrants in the French labor market. Mathematical Social Sciences. Volume 112, July 2021, Pages 61-71.

[14] Werner Roeger, Janos Varga, Jan in 'tVeld et al., 2021. The distributional impact of labour market reforms: A model-based assessment. European Economic Review. Volume 131, January 2021, 103638.

[15] David A.Hensher, 2020. Chapter 25 - Multimodal transport pricing with extensions to non-motorised transport. Bus Transport Demand, Economics, Contracting, and Policy 2020, Pages 309-321.

[16] S.Bista, I.Debache, B.Chaix, 2020. Physical activity and sedentary behaviour related to transport activity assessed with multiple body-worn accelerometers: the RECORD MultiSensor Study. Public Health. Volume 189, December 2020, Pages 144-152.

[17] Logistics transportation is often considered a mode transport which is used by train, tram, bus and other vehicles (Long T.Truong, GrahamcCurrie, 2019) 